DOI: http://dx.doi.org/10.9771/rc-ufba.v15i0.43254

\title{
COMPETÊNCIAS GERENCIAIS OBSERVADAS E ESPERADAS DO GESTOR PÚBLICO POR CONCLUINTES DE CONTABILIDADE
}

\author{
MANAGEMENT SKILLS OBSERVED AND EXPECTED OF THE PUBLIC MANAGER BY \\ CONCLUSIONS OF ACCOUNTING
}

\author{
Vilma Geni Slomski ${ }^{1}$ \\ Fundação Escola de Comércio Álvares \\ Penteado (FECAP) \\ vilma.geni@fecap.br \\ https://orcid.org/0000-0001-6346-8207

\section{Valmor Slomski} \\ Faculdade de Economia, Administração e \\ Contabilidade da Universidade de São Paulo \\ (FEA/USP) \\ valmor@usp.br \\ https://orcid.org/0000-0002-6755-293X
}

\author{
Thyago Serigue da Costa Nascimento \\ Faculdade Pan Amazônica (FAPAN) \\ thyagonascimento@yahoo.com.br \\ https://orcid.org/0000-0002-1793-8519
}

\author{
Nelson Felipe Tavares Sales Carrozzo \\ Faculdade Santa Lúcia (FSL) \\ prof.nelsoncarrozzo@outlook.com \\ https://orcid.org/0000-0002-5183-5572
}

\section{RESUMO}

Esta pesquisa teve como objetivo analisar as percepções sobre competências gerenciais observadas e esperadas do gestor público por concluintes de cursos de Ciências Contábeis de instituições de ensino superior privado de Belém (PA). Realizou-se uma pesquisa descritiva com abordagem quantitativa. A coleta dos dados ocorreu por meio de questionário e a análise por métodos estatísticos. Constatou-se que as competências gerenciais de maior expressividade foram "Saber ouvir", "Ética e transparência", "Cidadania e Democracia", "Responsabilidade", "Planejamento", "Comprometimento", "Visão estratégica", "Liderança" e "Negociação". Permite-se inferir que concluintes com ou sem experiência neste setor definem o gestor público como alguém com capacidade para ouvir, planejar e negociar, que seja comprometido, responsável, transparente e ético, que tenha visão estratégica e que exerça a liderança, a democracia e a cidadania na administração pública. Concluiu-se que no perfil do gestor público

\footnotetext{
${ }^{1}$ Praça General Araripe de Farias, 74, apto. 21 - Butantã - São Paulo-SP. CEP: 05590-020
} 
pesquisado são mais valorizadas as competências sociais e organizacionais (saber e saber-ser) do que as técnico-profissionais (saber-fazer).

Palavras-chave: Competências Gerenciais. Gestor Público. Concluintes. Ciências Contábeis.

\begin{abstract}
This research aimed to analyze the perceptions about management competencies observed and expected by the public manager by graduates of accounting science courses of private higher education institutions in Belém (PA). A descriptive research was conducted with a quantitative approach. Data collection occurred through a questionnaire and analysis by statistical methods. It was found that the management skills of greater expressiveness were "Knowing to hear", "Ethics and transparency", "Citizenship and Democracy", "Responsibility", "Planning", "Commitment", "Strategic Vision", "Leadership" and "Negotiation". This allows us to infer that concluders with or without experience in this sector define the public manager as someone with the capacity to listen, plan and negotiate, who is committed, responsible, transparent and ethical, that he has a strategic vision and who exercises the democracy and citizenship in public administration. Thus, it was concluded that in the profile of the public manager surveyed are more valued the social and organizational skills (knowledge and know-being) than the technical-professionals (know-how).
\end{abstract}

Keywords: Managerial Competencies. Public Manager. Conclusions. Accounting Sciences.

\title{
1 INTRODUÇÃO
}

A formação por competências tem sido a agenda na educação profissional e é uma exigência do mundo do trabalho. Segundo Ropé e Tanguy (1997), a pedagogia das competências surge com maior ênfase no âmbito das reformulações dos currículos dos cursos de graduação, instituídas pela Lei n. 9.394 (1996) que estabelece as diretrizes e bases da educação nacional. Pode-se dizer que as reformulações curriculares promovidas a partir do deslocamento da formação profissional de um olhar racional e técnico para uma visão mais complexa e abrangente objetivam uma aproximação maior entre o que a academia valoriza e o que o mundo do trabalho necessita (Pereira, 2013).

Todavia, transcorridos 20 anos da institucionalização da Lei de Diretrizes e Bases da educação nacional (LDB), faz-se necessário investigar a formação de profissionais para além das capacidades técnicas, levando-se em conta o domínio de conhecimentos, habilidades e valores necessários para enfrentar os desafios da profissão. Em acordo, Deluiz (2001, p. 1) um dos fatores que mais influenciaram na institucionalização da noção de competências "foram as transformações nas relações de produção". O perfil de competências requeridas dos profissionais da contemporaneidade mediante as exigências do mundo do trabalho vai além das capacidades técnico-científicas, demanda conhecimentos, habilidades e valores não especificados na legislação educacional, mas que conferem materialidade ao discurso do ensino por competências.

A busca pelo alinhamento entre o que a academia valoriza e o que o mundo do trabalho necessita é foco de interesse de pesquisas que tratam das mudanças curriculares e do modo como a noção de competência influencia na organização dos currículos dos cursos e na formação profissional (Deluiz, 2001; Fleury \& Fleury, 2004; Kato, 2007; Felizardo, 2010; Laffin, 2015; Kuenzer, 2017). No mundo do trabalho, as competências técnicas, cognitivas, socioafetivas e gerenciais, como ser capaz de identificar e resolver problemas, a partir de soluções criativas às novas situações que a realidade do trabalho coloca, a ética, a transparência, a responsabilidade, o planejamento, o comprometimento, a visão estratégica, a liderança, a 
adaptabilidade, a flexibilidade se tornam cada vez mais valorizadas. Neste novo perfil de competências requeridas dos profissionais, têm validade não apenas a objetividade (saberfazer), mas também a subjetividade (saber e saber-ser) do profissional.

A substituição do conceito de qualificação profissional pela noção de competências (Ramos, 2001; Zarifian, 2001; Le Boterf, 2003; Ruas, 2005) encontra respaldo na abordagem sociocultural de educação e em estudos relacionados com a Sociologia das profissões, tais como os de Meghnagi (1992), Manfredi (1998), Arruda (2000), Kuenzer (2003), Orletti (2007) e Felizardo (2010). Neste âmbito os estudos sobre competências gerenciais, em especial do gestor público, tornam-se relevantes.

A administração pública baseada no modelo burocrático vem sendo substituída pelo modelo gerencial (Keinert, 1994; Amaral, 2006; Bergue, 2010; Bresser-Pereira, 2010; Farias Filho \& Miranda, 2016; Valadão Júnior, Buzatto, Medeiros, \& Heinzmann, 2017). Estudos internacionais (Mclaughlin, Osborne, \& Chew, 2009; Thomas, 2012) se dão conta de que um novo paradigma deve fazer parte da gestão pública contemporânea e se apoiam no modelo gerencial como resposta ao modelo tradicional. Pesquisas relacionadas com o modelo gerencial destacam o valor do serviço público (Moore, 2002; Moore \& Beninton, 2010; Pollitt \& Bouckaert, 2004) e criticam a ineficiência e a ineficácia da gestão pública referente à forma de alocação dos recursos públicos (Alford \& Hughes, 2008; Alford, 2009), além de salientarem a governança digital (Dunleavy et al., 2006; Margetts, 2009) e a Nova Governança Pública (Bingham, Nabatchi, \& O'leary, 2005; Osborne, 2010; Osborne \& Brown, 2011).

Outros estudos relacionados à noção de competência foram também desenvolvidos (Deluiz, 2001; Zarifian, 2001; Le Boterf, 2003; Godoy, 2007; Kato, 2007; Patalas-Maliszewska \& Hochmeister, 2011; Sefiani et al., 2012; Dutra, 2016) com o objetivo de demonstrar a relevância da formação científica e tecnológica do trabalhador diante das exigências e desafios da modernidade que tem se tornado o centro das preocupações dos órgãos responsáveis pela profissionalização em diferentes espaços e, neste sentido, instituem mudanças a fim de alinhar os currículos dos cursos às reais necessidades dos estudantes (Deluiz, 2001).

Essa perspectiva de educação motivou a realização desta pesquisa por entender que ela poderá contribuir com dados que evidenciem a visão sobre as competências observadas e esperadas do gestor público pelo futuro profissional da Contabilidade, que poderá também atuar na área pública, na qual será, via de regra, um prestador de contas do gestor público. $\mathrm{O}$ concluinte teria, então, a oportunidade de avaliar suas próprias competências para atuar como Contador no setor público. Essa compreensão do tema em estudo motivou a realização desta pesquisa e, assim, a formulação do seguinte questionamento: Quais são as percepções sobre competências gerenciais observadas e esperadas do gestor público por concluintes de cursos de Ciências Contábeis em instituições privadas de ensino superior da região metropolitana de Belém-PA?

Tendo em vista a problemática apresentada, o objetivo geral deste estudo foi o de analisar as percepções sobre competências gerenciais observadas e esperadas do gestor público por concluintes de cursos de Ciências Contábeis em instituições privadas de ensino superior da região metropolitana de Belém-PA. Considera-se que a criação de um momento para avaliar um grupo sob o ponto de vista das competências (saberes, valores, habilidades) e poder, ao mesmo tempo, avaliar a si próprio, pode favorecer a reflexão sobre o estereótipo de que, em geral, há uma incompetência na área pública e de que nada funciona (Slomski, 2005).

Neste sentido, espera-se que esta pesquisa possa oferecer subsídios para uma reflexão mais ampla sobre aspectos relativos à formação por competências, na qual os coordenadores dos cursos de Ciências Contábeis oferecidos por instituições privadas de ensino, responsáveis por um número expressivo de alunos, possam realizar atualizações curriculares, a fim de 
encontrar caminhos mais assertivos na formação do Contador da contemporaneidade, em especial futuros prestadores de contas do gestor público.

\section{FUNDAMENTAÇÃO TEÓRICA}

Nesta seção serão discutidos temas como: a noção de competências; ensino por competência na educação superior; e o conceito de competências gerenciais necessárias ao gestor público.

\subsection{A noção de competências}

Existe um consenso de que os modos de organização e de gestão do trabalho imprimem especificidades e significados diferentes à categoria competências (Deluiz, 2001; Kato, 2007; Ricardo, 2010; Kuenzer, 2003, 2017, 2018a). Uma análise construtivista de competências profissionais associa-se ao processo de aprendizagem da profissão tendo em vista que a competência se expressa no pensar e no agir em um determinado contexto de ação (Ricardo, 2010), considerando os conhecimentos, as atitudes e valores que se acumulam e potencializam o pensar e o agir de cada indivíduo (Kuenzer, 2003). Deste ponto de vista, Kuenzer (2018b) destaca que, em vista dos avanços tecnológicos, o mundo do trabalho fica cada vez mais subjetivo, exigindo conhecimento, manuseio de máquinas e de equipamentos cada vez mais sofisticados. Além disso, a rigidez é substituída pela flexibilidade, a obediência pelo questionamento, de modo a desenvolver indivíduos mais autônomos capazes de usar o conhecimento de maneira interdisciplinar, a fim de identificar problemas e criar rapidamente soluções inovadoras para as diversas situações que a realidade e as relações de trabalho colocam cotidianamente (Kuenzer, 2018b). Deste ponto de vista as competências se desenvolvem em meio a situações complexas, comumente chamadas de situações-problema. Ressalta-se que esta análise parte do pressuposto de que "as formas históricas de organização e gestão da força de trabalho não se superam por substituição, mas sim por incorporação, criando diferentes modalidades de uso da força de trabalho que por sua vez demandam diferentes competências" (Kuenzer, 2003, p. 4).

Neste contexto, os sistemas de ensino implementaram reformulações curriculares com a adoção da noção de competências, estimulados pelas cobranças empresariais, imprimem por vezes interpretações econômicas ligadas ao desempenho e, então, a uma formação técnica no intuito de estreitar as relações entre o desenvolvimento econômico e o ensino superior. Em acordo Silva (2007, p. 4) explica que o desenvolvimento de competências se restringe a uma "noção essencialmente individual e identificável, seja nas ações práticas da vida, seja na dimensão das relações em geral ou especificamente no âmbito do trabalho".

Nesse sentido caminham as reformas do ensino superior implementadas pela Lei de Diretrizes e Bases n. 9.394/96, cujo inciso II do artigo 53, referente à Educação Superior, propõe a fixação dos currículos de seus cursos e programas, observadas as diretrizes gerais pertinentes. "Iniciou-se em 1996, uma reforma nos cursos de graduação, tendo como elemento basilar a flexibilidade curricular e a relação com o mundo do trabalho, visando à formação de pessoas mais aptas a assimilar mudanças e mais autônomas em suas escolhas" (Silva, 2007, p. 3). Em acordo Nunes e Patrus-Pena (2011) ressaltam que os componentes organizados e explícitos da formação do trabalhador, ou seja, a escolarização formal e os diplomas correspondentes, vêm sendo substituídos pela noção de competências. No modelo flexível de produção, segundo os autores, importa não só a posse dos saberes disciplinares escolares ou técnico-profissionais (qualificação formal), mas a capacidade de mobilizá-los para identificar e resolver de forma criativa problemas e imprevistos das situações de trabalho.

Conforme se observa, as competências gestadas no taylorismo/fordismo não são substituídas pelas formas flexíveis de organização e gestão do trabalho, mas sim incorporadas. 
Há, no Toyotismo, um sistema de organização da produção via automação, "combinação esta que passa a se constituir na estratégia para se obter ganhos de produtividade e, portanto, assegurar a competitividade" (Kuenzer, 2003, p. 5). De forma sintética, Kuenzer (2018b) delineia um perfil do trabalhador e do ensino por competências no modelo de produção flexível com suas demandas de competitividade e com a crescente incorporação de ciência e de tecnologia. Dessa forma, a certificação e o diploma não são mais suficientes para a inserção profissional e a empregabilidade. Nesse caso, o "saber-fazer" demanda além dos conhecimentos adquiridos, também as experiências acumuladas ao longo da atividade profissional. $\mathrm{O}$ adjetivo "operacional" tem implicações não apenas técnicas, os saberes terão que ser "validados", "confirmados pela formação e pelo controle das funções exercidas na empresa, pois apenas a titulação, praticamente entendida como a qualificação, não é mais garantia de competência" (Ricardo, 2010, p. 5).

Para Kuenzer (2018b, p. 6), este novo princípio educativo do trabalho exige uma transformação radical no projeto político-pedagógico das instituições de educação, com sérias implicações para a formação de professores. A adoção acrítica do "modelo de competências" na educação superior opõe-se à construção coletiva de um projeto de educação emancipador, capaz de considerar as distintas realidades, os distintos pontos de partida e as reais necessidades dos estudantes. Para Ricardo (2010), um projeto de educação capaz de pôr em prática a função social da educação deve ser eficaz em um pensamento complexo e sistêmico, em que as instituições de educação estejam abertas "à negociação e ao compartilhamento de discursos e trocas de experiências. Isso pode conduzir a um subjetivismo e a um relativismo epistemológico" (Ricardo, 2010, p. 8).

\subsection{O ensino por competência na educação superior: desafios da relação teoria e prática}

As competências profissionais assumem papel central nas políticas educacionais, em especial nas formuladas a partir da LDB (1996) e presentes nas diretrizes curriculares para os cursos de graduação. Todavia, a sua adoção tem ocorrido sem debate com os profissionais da educação, demais profissionais e alunos diretamente envolvidos. Isso demonstra a visão linear de ciência e o realismo epistemológico que permeia as decisões curriculares e, nesse âmbito, o processo de ensino-aprendizagem (Slomski, Gomes, \& Guimarães, 2010; Ricardo, 2010; Kuenzer, 2003, 2018a, 2018b). Isso implica dizer que a institucionalização por decreto das reformas curriculares pode não funcionar, uma vez que o conhecimento é produzido a partir das relações sociais que os homens estabelecem, sendo portanto, resultante das atividades práticas, "através das quais apreendem, compreendem e transformam as circunstâncias ao mesmo tempo em que são transformados por elas. Sendo, portanto, um processo objetivo, embora necessariamente mediado pela subjetividade" (Kuenzer, 2003, p. 3).

Nesse sentido, a competência define-se como "saber-agir, isto é, um saber integrar, mobilizar e saber aplicar um conjunto de recursos (conhecimentos, saberes, atitudes e raciocínios, etc.) em um contexto para enfrentar os diferentes problemas ou para realizar uma tarefa" (Le Boterf, 1995, p. 14). Estudos como os de Fleury e Fleury (2001), de Deluiz (2001), de Laffin (2015), de Lemos, Berni e Palmeira (2014), dentre outros, sugerem mudanças curriculares e processos pedagógicos voltados para o desenvolvimento de competências que instrumentalizem os alunos com conhecimentos, habilidades e valores necessários para enfrentar os desafios e as exigências da profissão.

Um dos desafios do ensino por competências na perspectiva da práxis é entender a categoria competência como sendo: "A capacidade de agir, em situações previstas e não previstas, com rapidez e eficiência, articulando conhecimentos tácitos e científicos a experiências pessoais e laborais vivenciadas ao longo da vida" (Kuenzer, 2003, p. 10). A necessária relação entre teoria e prática tem, como parâmetro, a ideia de que a prática é "o ato 
ou conjunto de atos através dos quais o sujeito modifica a matéria prima, independentemente de sua natureza, seja através do trabalho material ou não material” (Kuenzer, 2003, p. 11). Já a teoria, ou o trabalho intelectual, se constitui como "um movimento do pensamento que se debruça sobre a prática para apreendê-la e compreendê-la, de modo que não existe atividade teórica fora da prática", porém são coisas distintas, posto que a teoria "se atém ao plano do conhecimento ao produzir ideias, representações, conceitos" (Kuenzer, 2003, p. 11).

Além disso, um projeto de ensino deve abranger atributos individuais e sociais dos formandos em uma perspectiva não apenas objetiva, mas também subjetiva uma vez que a construção de competências se refere ao coletivo dos trabalhadores ou a dimensões coletivas e sociais (Deluiz, 2001, p. 6). A autora considera ainda que a matriz crítico-emancipatória está ainda em construção e tem seus fundamentos teóricos no pensamento crítico-dialético, que não só ressignifica a noção de competência, atribuindo-lhe um sentido que atenda aos interesses dos alunos e do mundo do trabalho, mas, principalmente, aponta princípios orientadores para a investigação dos processos de trabalho, para a organização do currículo e para a construção de propostas voltadas para a construção do perfil requerido dos profissionais da contemporaneidade (Deluiz, 2001). Nessa visão de educação, a noção de competência tem caráter "multidimensional" é uma construção balizada por parâmetros socioculturais e históricos. Para Deluiz (2001, p. 10) essas características não se confundem "com mero desempenho, dimensão individual, de caráter racional e técnico, antes envolvem conhecimentos (saberes) e também valores (saber-ser) que precisam ser desenvolvidos e aprimorados ao longo da vida.

\subsection{0 conceito de competências gerenciais}

A reestruturação do mundo do trabalho passou a requerer novos perfis profissionais, o que faz com que os processos de formação sejam repensados nos âmbitos das universidades, empresas e outras esferas educativas (Deluiz, 2001; Godoy, 2007). Nesse cenário, exige-se novas competências sociais e profissionais para um melhor alinhamento entre o mundo do trabalho e a academia.

No mundo do trabalho, o conceito de competência profissional torna-se cada vez mais complexo, uma vez que exige dos indivíduos a capacidade de "articular conhecimentos, habilidades e atitudes para a resolução de problemas num determinado campo de atuação" (Godoy, 2007, p. 1). Autores como Deluiz (2001), Zarifian (2001), Le Boterf (2003), Kato (2007) e Dutra (2016) corroboram esse pensamento ao entenderem que a abordagem da qualificação atrela a competência a uma perspectiva comportamentalista e associada às habilidades e capacidades referentes ao saber-fazer dos indivíduos. Deluiz (2001) explica que o perfil de competências requerido dos profissionais pelas organizações é uma resposta à constituição das formas de produção flexíveis e à "inovação científico-tecnológica aplicada aos processos produtivos, e de novos modos de gerenciamento da organização do trabalho e do saber dos trabalhadores. (Deluiz, 2001, P.1).

A abordagem por competências tem como objetivo, assim, deslocar o foco dos aspectos técnicos da profissionalização para os aspectos associados à subjetividade e às novas relações do trabalho. Kato (2007) diz que, ao se confrontar a noção de qualificação com a de competência, verificam-se abordagens opostas. De um lado está o ponto de vista da qualificação, com uma visão estática do mundo do trabalho, "baseada em saberes teóricos, nos diplomas, em profissões definidas, estáveis e duradouras que validavam a formação profissional" (Kato, 2007, p. 31). Do outro lado tem-se a visão que relaciona o termo competência aos novos "modelos de produção ligados à visão dinâmica e mutante do mundo do trabalho" (Kato, 2007, p. 31). Autores franceses, como Zarifian (2001) e Le Boterf (2003), e outros nacionais, como Deluiz (2001), Ruas (2001), Fleury e Fleury (2004) e Kato (2007), 
com base na teoria construtivista, destacam atividades e tarefas que se convertem em competências mobilizadas para atingir um desempenho satisfatório nas situações de trabalho. Para esses autores, as competências individuais se integram às coletivas e estas, à organização. Nessa perspectiva, Zarifian (2001) e Le Boterf (2003) mencionam a importância do saber mobilizar, saber fazer, saber agir, tomar iniciativa, assumir responsabilidades, ou seja, ressaltam a entrega efetiva ao trabalho em um sentido amplo e não restrito. Para Dutra (2016, p. 54), a competência define-se "como um conjunto de conhecimentos, habilidades e atitudes necessários para que a pessoa desenvolva suas atribulações e responsabilidades". Fleury e Fleury (2004) contribuem ao dizer que as competências dos indivíduos podem ser caracterizadas como gerenciais, à medida que conhecimentos, habilidades e atitudes são disponibilizados à empresa para ser possível mobilizar e integrar recursos e agregar valores.

Nesse sentido, "é a competência gerencial que mobiliza todas as outras competências organizacionais - as essenciais, as funcionais e as individuais" (Ruas, 2001, p. 247). A competência gerencial numa visão sistêmica engloba conhecimentos, habilidades e atitudes, agregando valores ao indivíduo e à organização. Dutra e Carvalho (2006, p. 103) afirmam que competência é a "capacidade da pessoa de agregar valor ao patrimônio de conhecimentos da organização". Fischer et al. (2010, p. 31) acrescentam que "o conceito de competência pode ser utilizado como referência para a construção de instrumentos de gestão e, também, como forma de gestão de pessoas na empresa".

Neste contexto, Watson (2005, p. 15) destaca a necessidade de mudança da lógica denominada sistêmico-controladora para a aplicação de modelos de gestão e uso de ferramentas que promovam a eficácia do trabalho gerencial e, assim, das organizações. Desse modo, propõe a possibilidade da utilização da lógica processual-relacional na gestão, apontando, inclusive, ser uma possibilidade que contribui para as "competências gerenciais na sociedade da informação" (Watson, 2005, p. 15).

\subsubsection{Competências gerenciais necessárias ao gestor público}

A mudança de um estado burocrático para uma administração pública gerencial, visando redefinir o papel do gestor em busca da modernização, exige, igualmente, uma formação profissional que supere o conceito de qualificação rumo à adoção da noção de competência (Ruas, 2001; Deluiz, 2001; Kuenzer, 2003; Chiavenato, 2004; Fleury \& Ruas, 2010). A administração pública tem sido questionada no que se refere à ineficácia dos serviços prestados, desse modo, o alcance da qualidade da gestão nesse setor, passa, obrigatoriamente, pelo mapeamento e pelo desenvolvimento das competências gerenciais. Para Rezende, Slomski e Corrar (2005, p. 89), a gestão pública gerencial é o "processo pelo qual os gestores da coisa pública passaram a se preocupar não só com a aplicação dos recursos de forma correta, sob o aspecto legal, mas também sob a ótica da eficácia e da eficiência na aplicação dos recursos públicos".

Nessa linha de pensamento, Amaral (2006, p. 2) acredita que, apesar das dificuldades, a prática mostra que "é possível desenvolver mudanças de hábito, de mentalidade, de estrutura, de comportamento e de regras, que melhoram objetivamente o padrão de qualidade dos serviços públicos". Essa assertiva aponta para a necessidade de mudança das estruturas hierarquizadas e burocráticas no setor público, que tendem a um processo de isolamento e de ineficácia dos serviços prestados. Isso significa dizer que, na sociedade do conhecimento e da informação, a posse dos saberes técnico-profissionais (qualificação formal) não é o bastante, sendo de grande importância a capacidade de mobilizá-los para resolver e enfrentar os imprevistos nas situações de trabalho. Dessa forma, assumem relevância as qualificações sociais e a subjetividade do trabalhador, componentes não organizados da formação que incluem habilidades cognitivas e comportamentais (Fleury \& Ruas, 2010). 
Longo (2003, p. 17) defende a profissionalização de líderes públicos, cujas competências deverão ser diversificadas e baseadas em um conjunto de "atributos", tais como: motivação, caráter, "autoconceito positivo", formação em valores, "capacidades cognitivas e de conduta". Essas características indicam que o contexto da administração pública requer uma mudança não apenas operacional, mas também cultural, de princípio e de valores, o que implica o desenvolvimento de uma identidade grupal. Essas sugestões de profissionalização dos dirigentes públicos fazem referência ao conjunto de aprendizagens construídas ao longo da vida, baseadas em capacidades cognitivas e afetivas, ou seja, de mobilização de habilidades, de valores e de conhecimentos em contexto.

Em acordo Newcomer (1999, p. 8) sugere que processos formativos dos gestores públicos sejam em "escolas de administração pública", a fim de que aprendam sobre o "funcionamento da máquina pública". A autora sugere um conjunto de competências que o gestor público precisaria desenvolver para a sua adequação aos objetivos das instituições públicas tais como:

1. Direito constitucional; 2. Ética; 3. A ética do serviço público; 4. Direito processual em gestão de recursos humanos; 5. Procedimentos de políticas de alocação de recursos em instituições governamentais e econômicas; 6 . Direito internacional; 7. Política de grupos de interesse; 8 . Modelagem econômica; 9. Teoria da gestão de pessoas (liderança); 10. Planejamento estratégico; 11. Mensuração de desempenho; 12 . Monitoramento de contratos; 13 . Utilização de dados sobre desempenho e avaliação para melhorar programas; 14. Prestação de contas sobre desempenho e dados; 15. Administração financeira, inclusive atividades de cálculo de custos; 16. Solução de conflitos e negociação; 17. Envolvimento dos cidadãos; 18. Criação de consenso; 19. Motivação de pessoal; 20. Análise de problemas e conhecimento de estatística e de custo-benefício. (Newcomer, 1999, p. 8).

Esse conjunto de competências que o gestor público deveria desenvolver e aprimorar para o alcance dos objetivos das instituições públicas nas quais atua indica exigências e desafios que precisam ser ultrapassados. Schwella $(2005$, p. 2) destaca que os gestores precisam saber trabalhar com questões da atualidade, como a "globalização", a "complexidade" dos problemas, as "desigualdades" econômicas e sociais, a "diversidade", a adoção de uma "boa governança", a "erosão da confiança", dentre outras. Para enfrentar os desafios que lhe são colocados, o autor sugere que o gestor público desenvolva um novo perfil de competências profissionais para o desempenho eficaz de suas atividades.

O estudo de Valadão Júnior et al. (2017, p. 8), sob o título de "Formação de Competências do Gestor Público", teve como objetivo avaliar o nível de coerência dos projetos político-pedagógicos dos cursos de graduação em administração pública com nota 5 no Exame Nacional de Desempenho de Estudantes (ENADE), bem como as competências profissionais dos concluintes na área pública. A pesquisa contemplou uma matriz com 20 competências necessárias ao gestor público, a saber:

1. Planejamento; 2. Visão Estratégica; 3. Visão Crítica; 4. Criatividade; 5. Inovação; 6. Identificar problemas; 7. Resolução de problemas; 8. Lidar com mudanças; 9. Tomada de decisão; 10. Competência Política; 11. Capacidade de Comunicação; 12. Tecnologias Administrativas; 13. Cooperação (trabalho em equipe); 14. Gerenciar conflitos; 15. Saber ouvir; 16. Comprometimento; 17. Liderança; 18. Responsabilidade; 19. Ética e Transparência; 20. Cidadania e Democracia. (Valadão Júnior et al., 2017, p. 8).

Outras pesquisas com base na gestão de pessoas investigaram as competências gerenciais necessárias ao gestor público, com destaque para a liderança. $\mathrm{O}$ estudo de Lemos et al. (2014) ressalta a importância do trabalho em equipe e a orientação por resultado no serviço público. Gomes, Xavier e Lemos (2015), além de reforçar esses comportamentos, concluem que a liderança favorece a integração entre gestores, servidores e os que buscam pelos serviços públicos. O estudo de Farias Filho e Miranda (2016) reforça o entendimento de que o estilo de 
liderança adotado pelo gestor público promove a integração entre as esferas de governo e os cidadãos.

\section{METODOLOGIA DA PESQUISA}

Tendo em vista que o objetivo deste estudo foi o de analisar as percepções sobre competências gerenciais observadas e esperadas do gestor público por concluintes do curso de Ciências Contábeis, entendeu-se que o modelo de pesquisa descritiva de abordagem quantitativa seria a opção mais adequada. Esta pesquisa classifica-se como quantitativa por utilizar instrumento de coleta de dados com questões estruturadas em vista do objetivo geral, que é o de captar e descrever por parâmetros estatísticos as percepções dos concluintes alvos deste estudo.

A pesquisa delimitou-se ao curso de bacharelado em Ciências Contábeis oferecido por 9 instituições de ensino superior (IES) privadas localizadas na região Amazônica do Brasil, assim distribuídas: a) 2 IES no município de Ananindeua; b) 7 faculdades localizadas no município de Belém do Pará. Os critérios de escolha das instituições foram: a) os cursos serem na modalidade presencial; b) os cursos terem o reconhecimento do Ministério da Educação (MEC); c) os cursos estarem em funcionamento há pelo menos 5 anos; d) os cursos possuírem pelo menos o conceito 3 no Exame Nacional de Desempenho dos Estudantes (ENADE); e) o fato de as IES serem localizadas na cidade onde reside o pesquisador e serem de livre acesso, facilitando, assim, a coleta dos dados. Ademais, a possibilidade de a pesquisa abranger mais de um município, o que corrobora com a obtenção de opiniões diversificadas da população investigada.

Quanto à amostra, optou-se, por conveniência, pesquisar os alunos concluintes regularmente matriculados nos cursos de Ciências Contábeis das 9 instituições de ensino superior (IES), o que somou 536 alunos, obtendo-se um total de 370 questionários válidos. Os dados foram coletados por meio de questionário aplicado in loco, composto por 26 questões estruturadas destas, 6 foram referentes a dados demográficos e 20 assertivas que compõem a matriz de competências gerenciais necessárias ao gestor público.

O instrumento dividiu-se em três partes com temáticas e questões conforme se detalha a seguir. A parte I teve como objetivo levantar o perfil dos respondentes a partir de questões como: a) sexo; b) idade; c) formação acadêmica; d) experiência na área pública, e) experiência em liderança ou função gerencial. A parte II teve como objetivo identificar competências gerenciais "observadas" no gestor público, tendo por base o questionário utilizado por Valadão Júnior et al. (2017, p. 8). Das 30 competências gerenciais presentes no questionário deste autor, selecionaram-se 20 assertivas. Diferentemente do estudo de Valadão Júnior et al. (2017), este avaliou as percepções de concluintes sobre competências gerenciais percebidas e esperadas do gestor público. A parte III do questionário teve como objetivo identificar competências gerenciais "esperadas" do gestor público e teve por base a mesma matriz utilizada na parte II deste questionário. Diferentemente da parte II, a parte III investigou perspectivas futuras, ou seja, o que os alunos esperam do profissional desta área do conhecimento que, no caso, pode ser ocupada por um Contador.

Para as partes II e III do questionário, utilizou-se uma escala Likert que buscou a percepção do concluinte quanto ao grau de importância do domínio dessas competências pelo gestor público a partir de 5 níveis: 1 - Irrelevante (I); 2 - Pouco Relevante (PR); 3 - Sem Opinião (SO); 4 - Relevante (R); 5 - Muito Relevante (MR). A base instrumental desta pesquisa foi o questionário, que buscou atender aos objetivos delineados e a questão de pesquisa formulada. Foram selecionadas 20 competências do estudo de Valadão Júnior et al. (2017) e classificadas segundo os 3 eixos de competências sugeridos por Fleury e Fleury (2001) e Ruas (2001), como demonstrado na Tabela 1. 
Tabela 1. Eixos de competências do gestor público

\section{1 - Eixo Organizacional}

1. Planejamento - Ter capacidade para planejar, implementar, monitorar e avaliar políticas, programas, planos e projetos públicos, sempre se comprometendo com a manutenção e o respeito às regras e aos valores democráticos;

2. Visão estratégica - Ter visão estratégica, considerando a especificidade do serviço público, vinculando-se às leis, políticas, programas e projetos da instituição pública;

3. Criatividade - Ter criatividade para gerar ideias, indo além do saber fazer, contribuindo para propor melhorias no processo de trabalho e na resolução de problemas;

4. Inovação - Inovar, colocando em ação as ideias que podem contribuir para melhorar a qualidade da gestão, bem como a satisfação da comunidade;

5. Negociação - Negociar, argumentar com a capacidade de se posicionar, visando alcançar os resultados que atendam ao interesse da sociedade;

6. Tomada de decisão - Tomar decisões, em diferentes graus de complexidade, levando em consideração todas as alternativas e os recursos disponíveis no contexto de trabalho.

\section{2 - Eixo Relacional / Social}

7. Visão crítica - Ter visão crítica, sendo capaz de avaliar os projetos e atividades de trabalho com a finalidade de promover melhorias;

8. Trabalho em equipe - Saber cooperar no ambiente de trabalho com conhecimentos, habilidades e atitudes;

9. Saber ouvir- Saber ouvir com respeito, tanto aos indivíduos que compõem a equipe de trabalho do órgão público quanto aos cidadãos que buscam pelos serviços prestados;

10. Liderança - Ter liderança para gerenciar pessoas e recursos, de modo a favorecer o bem comum;

11. Ética e transparência - Agir de acordo com os princípios da administração pública, respeitando as leis, normas, códigos de conduta profissional;

12. Cidadania e Democracia - Promover a cidadania, proporcionando à comunidade usufruir dos seus direitos com serviços de qualidade;

13. Gerenciar Conflitos - Saber compreender e tratar a diversidade de informações disponíveis no ambiente de trabalho, respeitando o princípio da transparência;

14. Comprometimento - Ter comprometimento no dia a dia de trabalho.

\section{3 - Eixo Técnico-profissional}

15. Resolução de problemas - Identificar e resolver problemas que impedem o pleno desenvolvimento do trabalho;

16. Mudança - Saber lidar com mudanças descontínuas no ambiente de trabalho;

17. Política - Ter competência política para administrar as relações de poder dentro do contexto de trabalho intra e interinstitucionais, atendendo aos interesses da sociedade;

18. Comunicação - Se comunicar de forma compreensível, para construir um entendimento recíproco, compartilhado e socializado dos saberes e informações no ambiente de trabalho, bem como com a sociedade;

19. Tecnologias Administrativas - Ter habilidade para desenvolver e utilizar tecnologias administrativas, de modo a gerar eficácia e eficiência no serviço público;

20. Responsabilidade - Assumir responsabilidade com o trabalho de sua competência, respondendo por suas iniciativas.

Fonte: Adaptado de Valadão Júnior et al. (2017, p. 8).

Para identificar a existência de pontos a serem melhorados no instrumento, foi realizado um pré-teste no mês de maio de 2018, com um grupo de cinco concluintes do curso de Ciências Contábeis de uma faculdade da região metropolitana de Belém, não incluída na amostra final. Após a aplicação, constatou-se que não houve dúvidas ou problemas para responder, não havendo, portanto, a necessidade de melhoria ou adequação do instrumento de pesquisa.

Quanto à coleta dos dados, em um primeiro momento, entrou-se em contato com os coordenadores das IES selecionadas, que designaram os professores que cederiam parte das suas aulas para aplicação do questionário in loco. Visando contemplar o maior número possível de alunos em sala, foram feitas visitas em dias alternados na mesma instituição. O questionário foi aplicado após a assinatura do termo de consentimento livre e esclarecido. 
Inicialmente os dados foram analisados pela estatística descritiva, com o intuito de caracterizar a amostra pesquisada. Em seguida, procedeu-se à análise fatorial das partes II e III do questionário, a fim de identificar a estrutura das relações entre as assertivas da escala Likert. Nessa última etapa, colocaram-se em foco dois grupos: o grupo que já trabalhou ou estagiou, e o grupo que não trabalhou nem estagiou na área pública. A análise fatorial procurou identificar as estruturas das relações entre as variáveis, buscando o menor conjunto possível de fatores, isto é, a reunião de proposições segundo a mesma tendência de correlação estatística (Malhotra, 2012).

O primeiro passo para a construção de uma análise fatorial é a realização dos testes de Kaiser-Meyer-Olkin (KMO) e de Bartlett. Esses testes são úteis para verificar se há adequabilidade dos dados para este tipo de método estatístico. O KMO é uma análise prévia da análise fatorial, é uma medida de "correlação parcial" (adequabilidade) dos dados sobre os quais se fará a análise fatorial. Assim, como o intuito é gerar fatores, o ideal é que haja uma "correlação" entre as variáveis, pois, assim, pode-se unir várias delas, criando-se os fatores. Segundo Maroco (2003, p. 268), a medida de KMO significa "correlação" e, dessa forma, refere-se ao seguinte critério de classificação: Inaceitável, variando de $\leq 0,4$ a 0,5; Medíocre, variando de $<0,5$ a 0,6; Média, variando de $<0,6$ a 0,7; Boa, variando de $<0,7$ a 0,85; Excelente, variando de $<0,85$ a 1.

Para complementar a análise inicial de uma fatorial, tem-se o Teste de Bartlett, que mede se a matriz de correlação dos dados é igual ou não à matriz identidade. Para utilizar a análise fatorial com bons resultados, deve-se rejeitar a hipótese nula, ou seja, de que a matriz de correlação seja igual à matriz identidade, pois, dessa forma, tem-se certeza de que existe correlação entre os dados. Eles receberam os tratamentos estatísticos disponíveis no Statistical Package for Social Sciences (SPSS 25.0) e no programa estatístico R-STUDIO 1.0.153.

\section{RESULTADOS E DISCUSSÕES}

Tendo em vista os dados advindos da aplicação do questionário, procederam-se às análises e extraíram-se os seguintes temas: a) um perfil dos respondentes; b) competências gerenciais observadas e esperadas; c) competências gerenciais mais observadas e mais esperadas do gestor público.

\subsection{Perfil dos colaboradores da pesquisa}

Após análise descritiva dos dados, constatou-se o que se segue. Dos 370 alunos pesquisados, 210 (57\%) são do sexo feminino e 160 (43\%) do sexo masculino, não havendo predominância estatística quanto ao sexo. A maioria possui mais de 23 anos, 225 (61\%), e apenas $53(14 \%)$ possuem uma segunda graduação. Quando se analisa a experiência dos respondentes na área pública, observa-se que 162 (44\%) já estagiaram ou trabalharam nela. Quanto às áreas em que atuaram com mais frequência, 39 (11\%) afirmaram ter trabalhado na estrutura administrativa municipal, seguidos de 21 (6\%) na União, 35 (9\%) no estado e 136 (18\%) atuaram em outros departamentos da estrutura pública. Dentre os cargos que ocuparam, apenas 41 respondentes (11\%) exerceram o cargo de Diretor ou de Gerente. Desse total, 19 respondentes $(5 \%)$ permaneceram na função por um período de 1 a 6 anos.

Constatou-se um perfil de concluintes ainda jovens, na sua maioria mulheres e um percentual baixo de concluintes que possuem uma segunda graduação, experiência na área pública e que tenham exercido cargo de gestão. Esses resultados permitem presumir que os respondentes não vislumbram atuar na área pública. $\mathrm{O}$ curso de graduação em Ciências Contábeis habilita o concluinte a atuar em diferentes áreas, privada ou pública, bem como em qualquer estrutura administrativa. De acordo com a Resolução do CFC n. 560/83, a formação acadêmica do aluno deve habilitá-lo para o exercício da profissão em diferentes áreas da 
Contabilidade. Esses dados corroboram o entendimento de Slomski (2005) ao ressaltar a necessidade de gestores públicos conhecerem a área e terem maior preparo, pois, muitas vezes, profissionais não habilitados são contratados para atuar nesse setor.

\subsection{Competências gerenciais observadas e esperadas}

Quanto à percepção dos respondentes diante da matriz de competências gerenciais necessárias ao gestor da área pública, constatou-se que o grupo que trabalhou e o que não trabalhou em função do observado possui pensamentos convergentes, pois os formatos iguais entre as linhas evidenciam similaridade no que os concluintes observam sobre competências gerenciais necessárias (Figura 1).

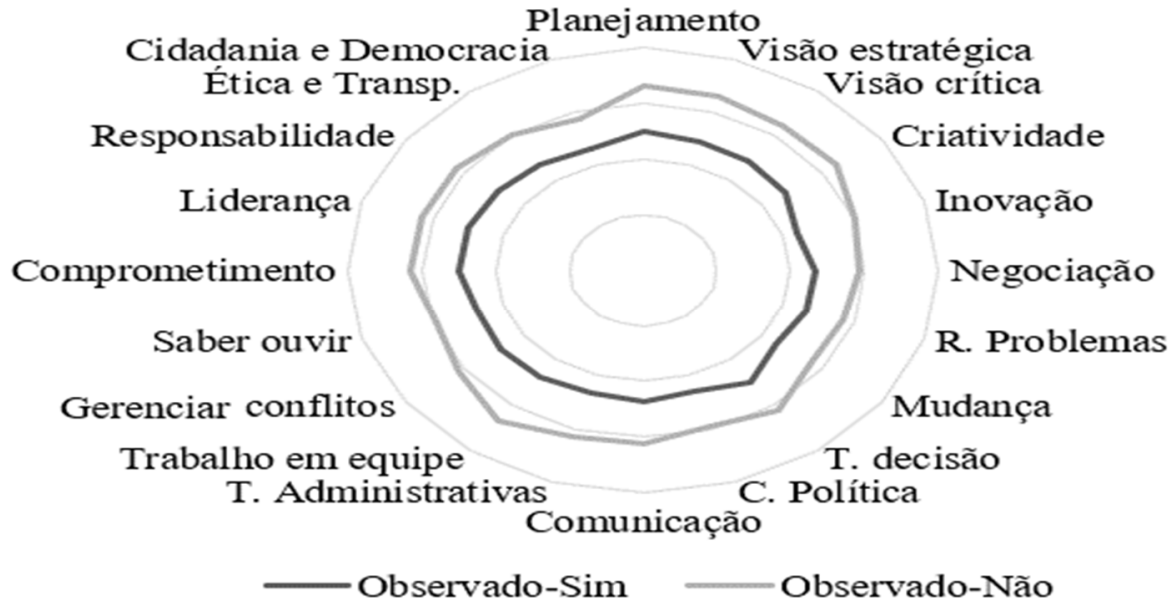

Figura 1. Competências gerenciais observadas.

Fonte: autores com base na pesquisa.

Já quanto ao esperado, a Figura 2 mostra as percepções dos respondentes diante da matriz de competências gerenciais necessárias ao gestor público, no que se constatou uma convergência de pensamentos entre o grupo que trabalhou e o que não trabalhou. Nesse caso, a saliência aproximada nas linhas de tendência evidencia um pensamento convergente dos dois grupos de concluintes sobre o esperado do gestor da área pública, conforme Figura 2.

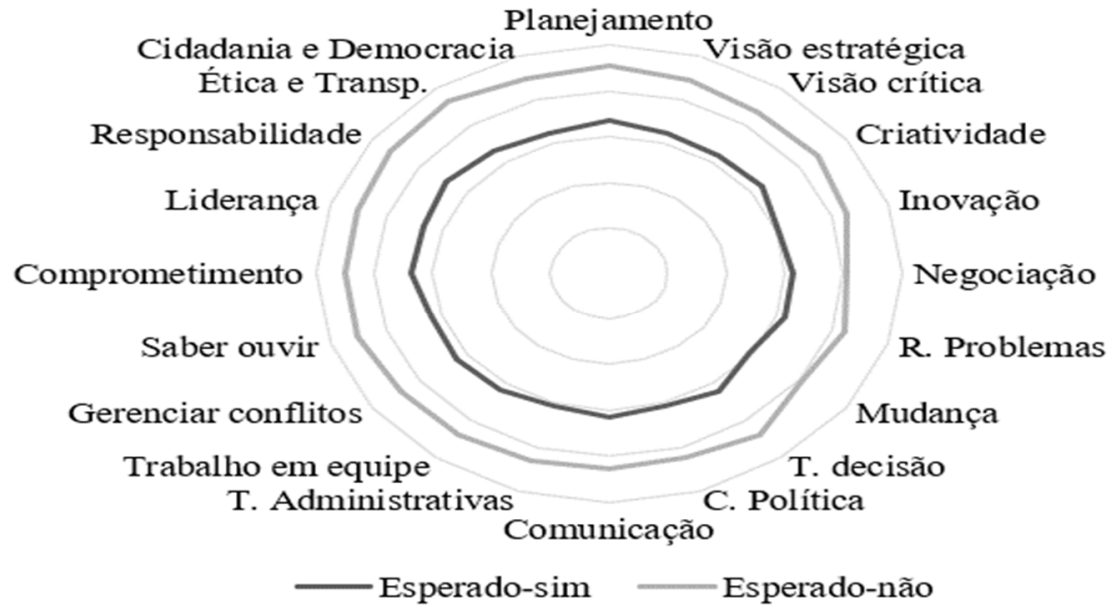

Figura 2. Competências gerenciais esperadas. Fonte: autores com base na pesquisa. 
Esses resultados estão em acordo com Godoy (2007) ao afirmar que no mundo do trabalho o conceito de competência profissional torna-se cada vez mais complexo, exigindo dos indivíduos a capacidade de reconhecer e de adquirir não apenas habilidades, mas também conhecimentos e atitudes para a resolução de problemas em um determinado campo de atuação. No caso da gestão pública, na mudança de uma administração baseada no modelo burocrático para uma administração gerencial (Bresser-Pereira, 2010), ganha relevância o conceito de competências, em oposição ao de qualificação e de gestão estratégica de pessoas (Amaral, 2006; Bergue, 2010).

\subsection{Competências gerenciais mais observadas e mais esperadas}

Para alcançar o que o grupo que trabalhou e o que não trabalhou mais observam e mais esperam do gestor que atua na área pública, foi aplicada a análise fatorial.

A aplicação está dividida em dois momentos: $1^{\circ}$ ) Num primeiro momento realizou-se a análise fatorial do grupo que já trabalhou ou estagiou na área pública e dos que não atuaram ainda baseando-se nas competências Observadas; $2^{\circ}$ ) Após realizou-se a análise fatorial do grupo que já trabalhou ou estagiou na área pública e do que não atuou com base nas competências Esperadas.

As Tabelas 2 e 3 evidenciam os testes de KMO e de esfericidade de Bartlett. O KMO acima de 0,850 é excelente (Maroco, 2003), entendendo-se que a amostra é adequada para o início do estudo. No Teste de Bartlett, com o nível de significância de 0,000 menor que 5\%, verifica-se a independência dos dados baseada na matriz identidade. Portanto, a análise fatorial é viável.

Tabela 2. Teste de KMO e Bartlett em função do Observado

\begin{tabular}{llll}
\hline & & \multicolumn{1}{l}{ Sim } & \multicolumn{1}{l}{ Não } \\
\hline Medida Kaiser-Meyer-Olkin de adequação de amostragem & & 0.952 & 0.943 \\
Teste de esfericidade de Bartlett & Aprox. Qui-quadrado & 190.000 & 190.000 \\
& Sig. & 0.000 & 0.000 \\
\hline
\end{tabular}

Fonte: autores com base na pesquisa.

Tabela 3. Teste de KMO e Bartlett em função do Esperado

\begin{tabular}{llll}
\hline & & Sim & \multicolumn{1}{l}{ Não } \\
\hline Medida Kaiser-Meyer-Olkin de adequação de amostragem & & 0.957 & 0.958 \\
Teste de esfericidade de Bartlett & Aprox. Qui-quadrado & 3102.073 & 4139.002 \\
& Sig. & 0.000 & 0.000 \\
\hline
\end{tabular}

Fonte: Autores com base na pesquisa.

A comunalidade representa, para o estudo, a variação explicada por variável, ou seja, quais variáveis explicam melhor os dados, conforme evidenciado nas Tabelas 4 e 5. Quanto às competências mais observadas (Tabela 4), para os respondentes que já trabalharam (Comunalidades Sim), as 3 variáveis mais expressivas para o estudo são: $1^{\circ}$ Saber ouvir com $0,743 \% ; 2^{\circ}$ Ética e transparência com $0,717 \%$; e $3^{\circ}$ Cidadania e Democracia com $0,705 \%$. Isso significa dizer que os respondentes valorizam mais a atenção e o respeito dispensados pelos gestores públicos, tanto aos integrantes da sua equipe de trabalho nos órgãos públicos, quanto aos cidadãos que buscam por esses serviços. Sendo assim, este grupo de concluintes valoriza o gestor da área pública que sabe ouvir, que pratica a ética, a transparência, a democracia e o exercício da cidadania.

Esses achados convergem: com o estudo de Keinert (1994), que destaca, no eixo das "capacidades humanas", o exercício da liderança, da comunicação, da negociação e da administração de conflitos; com o estudo de Newcomer (1999), que destaca a "teoria da gestão de pessoas e o exercício da liderança" como um dos conteúdos da formação do gestor público; 
e com o estudo de Amaral (2006) que, no eixo das competências gerenciais, destaca a "gestão de pessoas". Esse perfil de competências necessárias ao gestor público condiz com uma formação em valores, com um saber ser no contexto do serviço público. Esses resultados convergem com o que afirmam Deluiz (2001), Zarifian (2001), Le Boterf (2003), Kato (2007) e Dutra (2016), pois, para esses autores, a formação por competências associa-se a valores, a conhecimentos e a habilidades, não apenas a capacidades referentes ao saber-fazer dos indivíduos.

Tabela 4. Competências gerenciais mais observadas no gestor público

\begin{tabular}{lcc}
\hline \multicolumn{1}{c}{ Competências gerenciais } & Comunalidades Sim & Comunalidades Não \\
\hline Planejamento & 0.611 & $\mathbf{0 . 7 8 9}$ \\
Visão estratégica & 0.624 & $\mathbf{0 . 7 7 7}$ \\
Visão crítica & 0.565 & $\mathbf{0 . 7 4 8}$ \\
Criatividade & 0.562 & $\mathbf{0 . 7 1 2}$ \\
Inovação & 0.442 & 0.652 \\
Negociação & 0.492 & 0.614 \\
Resolução de Problemas & 0.599 & 0.611 \\
Mudança & 0.388 & 0.460 \\
Tomada de decisão & 0.539 & 0.566 \\
Competência Política & 0.530 & 0.527 \\
Comunicação & 0.633 & 0.487 \\
Tecnologias Administrativas & 0.562 & 0.562 \\
Trabalho em equipe & 0.618 & $\mathbf{0 . 7 1 7}$ \\
Gerenciar conflitos & 0.637 & 0.601 \\
Saber ouvir & $\mathbf{0 . 7 4 3}$ & $\mathbf{0 . 7 1 0}$ \\
Comprometimento & 0.670 & $\mathbf{0 . 7 0 7}$ \\
Liderança & 0.694 & 0.645 \\
Responsabilidade & 0.647 & $\mathbf{0 . 8 0 2}$ \\
Ética e Transparência & $\mathbf{0 . 7 1 7}$ & $\mathbf{0 . 7 6 9}$ \\
Cidadania e Democracia & $\mathbf{0 . 7 0 5}$ & $\mathbf{0 . 7 1 5}$ \\
\hline
\end{tabular}

Fonte: Autores com base na pesquisa.

Já para os concluintes que ainda não trabalharam (Tabela 4), das 20 variáveis (competências observadas), 10 são expressivas, conforme a seguinte ordem de destaque: $1^{\circ}$ Responsabilidade com $0,802 \% ; 2^{\circ}$ Planejamento com $0,789 \% ; 3^{\circ}$ Visão estratégica com $0,777 \% ; 4^{\circ}$ Ética e Transparência com $0,769 \% ; 5^{\circ}$ Visão crítica com $0,748 \% ; 6^{\circ}$ Trabalho em Equipe com $0,717 \% ; 7^{\circ}$ Cidadania e Democracia com $0,715 \% ; 8^{\circ}$ Criatividade com $0,712 \% ; 9^{\circ}$ Saber Ouvir com $0,710 \%$; e $10^{\circ}$ Comprometimento com $0,707 \%$. Nota-se que o grupo que não atuou identifica conhecimentos, valores e habilidades diferentes no gestor público, entretanto o foco centra-se em uma formação que contemple mais a dimensão social e a organizacional do que a técnico-profissional.

Pode-se dizer que o perfil identificado, em acordo com as competências mais expressivas, tem por maior relevância a capacidade do gestor em assumir "responsabilidade" com o trabalho de sua competência, respondendo por suas iniciativas, conforme o estudo de Valadão Júnior et al. (2017). Desse modo, ele deve ser responsável, ter planejamento, visão estratégica, ética e transparência, visão crítica e comprometimento, deve saber ouvir, negociar, trabalhar em equipe e promover a criatividade, a democracia e a cidadania. Essas características indicam que o olhar dos alunos está focado não apenas nas capacidades técnico-profissionais, mas no entendimento de que o setor exige gestores com "capacidade de diagnóstico, de solução de problemas, capacidade de tomar decisões, de intervir no processo de trabalho, de trabalhar em equipe, auto-organizar-se e enfrentar situações em constantes mudanças" (Deluiz, 2001, p. 2).

Esses achados corroboram o estudo de Souza (1994) ao afirmar que as mudanças se referem ao processo decisório e se desenvolvem a partir de duas perspectivas que devem ser complementares, de um lado alterações na estrutura organizacional e de outro modificações de 
cunho comportamental. Nesse contexto, o estudo de Amaral (2006, p. 9) sugere o desenvolvimento de 40 competências aos profissionais da área pública, destacando, no eixo das competências fundamentais/genéricas, o "conhecimento da máquina pública" e o "comprometimento com o serviço público". Para Newcomer (1999), os conhecimentos em Contabilidade não são os mesmos no setor público e no privado. Os gestores públicos têm de ser "fluentes na terminologia usada pelos gerentes do setor privado, pelos especialistas em informática e na linguagem política e governamental" de cada época (Newcomer, 1999, p. 11).

Assim, constata-se que, para os concluintes investigados, o gestor público deve possuir uma formação que o capacite para a gestão da "coisa pública". Slomski (2005) corrobora esse pensamento ao afirmar que pensar na gestão da coisa pública é, em primeiro lugar, pensar nas pessoas, "para o gestor público ter sucesso é preciso que ele conheça quem são, quantos são, quais são suas habilidades (...)" (Slomski, 2005, p. 50). Na função pública, os atributos eficiência, eficácia e profissionalização são intrínsecos à nova administração pública, bem como à nova Contabilidade Pública no Brasil.

Quanto às competências mais esperadas do gestor público contemporâneo pelos concluintes que já trabalharam, os dados da Tabela 5 indicam que, para o grupo com experiência, 6 são as variáveis (competências esperadas) mais expressivas para o estudo: $1^{\circ}$ Comprometimento $(0,791 \%) ; 2^{\circ}$ Responsabilidade $(0,770 \%) ; 3^{\circ}$ Liderança $(0,764 \%) ; 4^{\circ}$ Visão estratégica $(0,754 \%)$; $5^{\circ}$ Ética e Transparência $(0,722 \%)$; e $6^{\circ}$ Cidadania e Democracia $(0720 \%)$. Pode-se dizer que este grupo almeja um gestor público comprometido com o dia a dia do trabalho, acima de qualquer coisa. Nesse sentido, esse grupo espera um gestor comprometido e responsável, que tenha visão estratégica, ética, transparência e que exerça a liderança, a cidadania e a democracia.

As percepções desse grupo convergem com o estudo de Keinert (1994), o qual, no eixo das capacidades públicas, destaca a responsabilidade social baseada em noções de ética, democracia e de compromisso com um projeto político nacional fundado na noção de cidadania; e com o estudo de Amaral (2006), o qual, no eixo das competências fundamentais/genéricas, destaca o "comprometimento com o serviço público". Esses resultados estão em acordo também com o estudo de Santos, Laimer e Laimer (2016), o qual conclui que o fator agregador dos processos internos de mudança da administração pública se dá pelo melhor atendimento às crescentes demandas sociais, as quais exigem a modernização e a evolução do pensar a administração pública por gestores capacitados e comprometidos.

Já para os concluintes que ainda não trabalharam (Tabela 5), das 20 variáveis (competências esperadas), 15 são expressivas, obedecendo a seguinte ordem: $1^{\circ}$ Visão estratégica $(0,828 \%) ; 2^{\circ}$ Negociação $(0,810 \%) ; 3^{\circ}$ Ética e Transparência $(0,800 \%) ; 4^{\circ}$ Planejamento $(0,797 \%) ; 5^{\circ}$ Responsabilidade $(0,781 \%) ; 6^{\circ}$ Criatividade $(0,751 \%) ; 7^{\circ}$ Comprometimento $(0,738 \%) ; 8^{\circ}$ Saber ouvir $(0,737 \%) ; 9^{\circ}$ Gerenciar Conflitos $(0,731 \%) ; 10^{\circ}$ Visão crítica $(0,729 \%) ; 11^{\circ}$ Inovação $(0,727 \%) ; 12^{\circ}$ Liderança $(0,720 \%) ; 13^{\circ}$ Cidadania e Democracia (0,704\%); $14^{\circ}$ Tecnologias Administrativas (0,703\%); e $15^{\circ}$ Resolução de Problemas $(0,701 \%)$. Para esses concluintes, a visão estratégica exerce a maior relevância na preservação da especificidade da formação do gestor público, uma vez que as propostas de governo implementadas precisam considerar e aprimorar as leis, os programas e os projetos já em execução. Constata-se que tanto o primeiro quanto o segundo grupo almejam uma formação mais gerencial e atitudinal do que técnica do gestor público, muito mais relacionada com valores (atitudes) e conhecimentos (saberes) do que com habilidades (saber-fazer).

Portanto, enquanto o primeiro grupo almeja, sobretudo, um gestor público que seja comprometido, responsável, que tenha visão estratégica e que exerça a liderança, a ética, a transparência, a cidadania e a democracia, o segundo grupo considera mais relevante um gestor 
que tenha visão estratégica, planejamento, que saiba negociar, que seja transparente, responsável e criativo.

Tabela 5. Competências gerenciais mais esperadas do gestor público

\begin{tabular}{llc}
\hline Competências gerenciais & Comunalidades Sim & Comunalidades Não \\
\hline 1. Planejamento & 0.698 & $\mathbf{0 . 7 9 7}$ \\
2. Visão estratégica & $\mathbf{0 . 7 5 4}$ & $\mathbf{0 . 8 2 8}$ \\
3. Visão crítica & 0.577 & $\mathbf{0 . 7 2 9}$ \\
4. Criatividade & 0.656 & $\mathbf{0 . 7 5 1}$ \\
5. Inovação & 0.578 & $\mathbf{0 . 7 2 7}$ \\
6. Negociação & 0.614 & $\mathbf{0 . 8 1 0}$ \\
7. Resolução de Problemas & 0.585 & $\mathbf{0 . 7 0 1}$ \\
8. Mudança & 0.506 & 0.501 \\
9. Tomada de decisão & 0.634 & 0.687 \\
10. Competência Política & 0.560 & 0.525 \\
11. Comunicação & 0.682 & 0.647 \\
12. Tecnologias Administrativas & 0.516 & $\mathbf{0 . 7 0 3}$ \\
13. Trabalho em equipe & 0.688 & 0.662 \\
14. Gerenciar conflitos & 0.641 & $\mathbf{0 . 7 3 1}$ \\
15. Saber ouvir & 0.676 & $\mathbf{0 . 7 3 7}$ \\
16. Comprometimento & $\mathbf{0 . 7 9 1}$ & $\mathbf{0 . 7 3 8}$ \\
17. Liderança & $\mathbf{0 . 7 6 4}$ & $\mathbf{0 . 7 2 0}$ \\
18. Responsabilidade & $\mathbf{0 . 7 7 0}$ & $\mathbf{0 . 7 8 1}$ \\
19. Ética e Transparência & $\mathbf{0 . 7 2 2}$ & $\mathbf{0 . 8 0 0}$ \\
20. Cidadania e Democracia & $\mathbf{0 . 7 2 0}$ & $\mathbf{0 . 7 0 4}$ \\
\hline
\end{tabular}

Fonte: Autores com base na pesquisa.

Comprometimento e visão estratégica foram os que moveram, em primeiro lugar, as expectativas dos dois grupos. Esses achados convergem com o estudo de Keinert (1994, p.48), que destaca capacidades profissionais que propiciem "visão estratégica", criatividade e inovação e, no eixo capacidades públicas, que propiciem o "compromisso" com um projeto político nacional fundado na noção de cidadania. O estudo de Newcomer (1999, p. 8) destaca o "planejamento estratégico" e a "prestação de contas sobre desempenho", já o de Amaral (2006, p. 2), na dimensão da formação fundamental/genérica, cita o comprometimento com o serviço público e, na dimensão organizacional, cita "visão sistêmica" e integrada da Administração pública.

Esses achados corroboram também o estudo de Farias Filho e Miranda (2016), que constatou a necessidade de o gestor público possuir visão crítica e estar inserido no contexto global e local, bem como estar apto a trabalhar as diversidades existentes na administração pública, envolvendo todos os níveis da organização. Fato esse que permite a inovação dos serviços públicos ao procurar direcionar seu foco de atuação para o âmbito das necessidades sociais, ouvir a comunidade e servir de ponte necessária para a resolução de problemas.

Os resultados deste estudo se alinham com os resultados encontrados pelo estudo de Valadão Júnior et al. (2017, p.8), o qual serviu de base para esta pesquisa. Nele, as competências que mais se destacaram foram "comprometimento", "saber ouvir" e "ética". As competências "saber ouvir" e "comprometimento" foram as mais expressivas no grupo dos respondentes que já estagiou na área pública, e as competências "responsabilidade" e "visão estratégica" se destacaram no grupo que ainda não trabalhou ou estagiou no setor.

Entretanto, na presente pesquisa, tiveram maior expressividade outras competências, tais como: "transparência", "cidadania, democracia", "responsabilidade", "planejamento", 
"visão estratégica", "liderança" e "negociação". Essas competências foram as mais observadas e esperadas do gestor público pela amostra do estudo. Isso significa dizer que os concluintes investigados com ou sem experiência observam e esperam um perfil de gestor que saiba ouvir, planejar e negociar, que seja comprometido, responsável, transparente e ético, que tenha visão estratégica e que exerça a liderança, a cidadania e a democracia na administração pública.

Esse perfil de competências profissionais mais valorizadas e almejadas do gestor público pelos investigados pertence, sobretudo, às dimensões social e organizacional, além de técnico-profissional. Tais resultados indicam que as percepções observadas e esperadas dos grupos convergem, já que desejam uma administração pública com discursos e práticas que atendam aos anseios da população (Bresser-Pereira, 2010). Para Watson (2005), a lógica processual-relacional apresenta-se como alternativa às formas tradicionais e se volta às organizações e ao trabalho gerencial.

O ensino por competências se apresenta como um caminho para a emancipação e a autonomia do trabalhador desde que ocorra mudança da prática docente, ressaltando-se, assim, a necessidade de fazer da universidade um espaço privilegiado para a construção e difusão do conhecimento. Pesquisadores e professores comprometidos com a educação do trabalhador (Santos, Laimer, \& Laimer, 2016; Deluiz, 2001; Zarifian, 2001; Le Boterf, 2003; Godoy, 2007; Kato, 2007; Patalas-Maliszewska \& Hochmeister, 2011; Sefiani et al., 2012; Dutra, 2016) defendem uma noção de competência para além das dimensões econômicas e apontam para uma formação humana que auxilie no enfrentamento dos desafios promovidos pelas inovações tecnológicas e organizacionais, em que uma formação cultural ampla seja capaz de superar o desencontro que ocorre entre o mundo da educação e o mundo do trabalho.

\section{CONCLUSÕES}

Este estudo teve como objetivo analisar as percepções sobre competências gerenciais observadas e esperadas do gestor público por concluintes do curso de Ciências Contábeis, procurando-se evidenciar que competências se fazem necessárias na gestão pública da contemporaneidade sob a ótica de futuros Contadores. Foi possível identificar um perfil de concluintes ainda jovem, na sua maioria mulheres, e um percentual baixo de concluintes que possuem uma segunda graduação, experiência na área pública e que tenha exercido cargo de gestão. Esses resultados permitem presumir que os respondentes não vislumbram atuar na área pública.

Neste estudo, as competências gerenciais observadas e esperadas do gestor público de maior expressividade foram: "Saber ouvir"; "Ética e Transparência"; "Cidadania e Democracia" "Responsabilidade"; "Planejamento"; "Comprometimento"; "Visão estratégica"; "Liderança" e "Negociação". Esses resultados permitem dizer que os concluintes com ou sem experiência observam e esperam um perfil de gestor que saiba ouvir, planejar e negociar, que seja comprometido, responsável, transparente e ético, que tenha visão estratégica e que exerça a liderança, a democracia e a cidadania na administração pública. Esses dados permitem concluir que os alunos observam e esperam um gestor público com maior domínio de competências do âmbito gerencial e atitudinal, relacionadas mais com valores (atitudes) e conhecimentos (saberes) do que com o lado técnico-profissional (saber-fazer).

Pode-se dizer, então, que a formação universitária com foco apenas no mercado de trabalho precisa ser repensada. O ensino por competência, por sua vez, volta-se para uma formação em valores, conhecimentos e habilidades que tornam os acadêmicos capazes de fazer escolhas mais conscientes diante das áreas em que o curso de graduação lhes permite atuar como profissionais.

Como pesquisa futura, sugere-se a continuidade deste estudo em outras regiões do país, considerando outras áreas do conhecimento. Indica-se também a inclusão de pelo menos uma 
questão discursiva no questionário de coleta de dados, como uma forma de dar voz aos alunos, para que possam colocar livremente suas ideias sobre o que pensam e percebem do gestor público, obtendo-se, assim, maiores informações sobre o ensino por competências e sua institucionalização na educação superior. Estas seriam uma forma de saber com quais projetos de educação superior as instituições de ensino estão, de fato, comprometidas, tendo em vista o mundo do trabalho e os projetos dos alunos a partir da autonomia e da flexibilidade concedidas às instituições pela Lei de Diretrizes Bases Nacionais (LDB), em vigor há mais de duas décadas.

\section{REFERÊNCIAS}

Alford, J. (2009). Engaging public sector clients: from service-delivery to co-production. Basingstoke, UK: Palgrave.

Alford, J., \& Hughes, O. (2008). Public value pragmatism as the next phase of public management. American Review of Public Administration, Suffolk University, 38(2), 130148.

Amaral, H. K. D. (2006). Desenvolvimento de competências de servidores na administração pública brasileira. Revista do Serviço Público Brasília, 57(4), 549-563.

Arruda, M. C. (2000). Qualificação versus competência. Boletim Técnico do SENAC, 26(2), 1827.

Bergue, S. T. (2010). Gestão de pessoas em organizações públicas. 3, Caxias do Sul: Editora EDUCS.

Bingham, L., Nabatchi, T., \& O'leary, R. (2005). The new governance: practices and processes for stakeholder and citizen participation in the work of government. Public Administration Review, 85, 547-558.

Bresser-Pereira, L. C. (2010). A construção política do Estado. Lua Nova, 0102-6445(81), 117 146. Recuperado de http://www.scielo.br/scielo.php?pid=S0102-64452010000300006\& script=sci_abstract\&tlng=es.

Chiavenato, I. (2004). Comportamento organizacional: a dinâmica do sucesso das organizações. São Paulo: Pioneira Thomson Learning.

Deluiz, N. (2001). O modelo das competências profissionais no mundo do trabalho e na educação: implicações para o currículo. Boletim Técnico do SENAC, 27(3), 13-25.

Dunleavy, P., Margetts, H., Bastow, S., \& Tinkler, J. (2006). New public management is deadLong live digital-era governance. Journal of Public Administration Research and Theory, $16,467-494$.

Dutra, J. S. (2016). Gestão de pessoas-modelo, processos, tendências e perspectivas. São Paulo: Editora Atlas. 
Dutra, T. N. A., \& Carvalho, A. V. (2006). O profissional da informação e as habilidades exigidas pelo mercado de trabalho emergente. Revista Eletrônica Biblioteconomia, 11(22), 178-193.

Farias Filho, M. C., \& Miranda, S. M. (2016). Práticas inovadoras e estilo de liderança na gestão pública municipal paraense. Revista Pretexto, 17(4), 65-80.

Felizardo, J. M. (2010). Capitalismo, organização do trabalho e tecnologia da produção e seus impactos na qualificação da força de trabalho. Revista Labor, 1(3), 1-27.

Fischer, A. L., Dutra, J. S., Ruas, R. De L., \& Nakata, L. E. (2010). Absorção do conceito de competência em gestão de pessoas: A percepção dos profissionais e as orientações adotadas pelas empresas. Anais do Encontro Nacional da Associação Nacional de Pós-Graduação e Pesquisa em Administração. Salvador, BA, Brasil, 30.

Fleury, M. T. L., \& Fleury, A. C. C. (2001). Construindo o conceito de competência. Revista de Administração Contemporânea, 5(spe), 183-196.

Fleury, M. T. L., \& Fleury, A. C. C. (2004). Alinhando estratégia e competências. Revista de Administração de Empresas, 44(1), 44-57.

Fleury, M. T. L., \& Ruas, R. (2010). Competências, conceitos, métodos e experiências. São Paulo: Editora Atlas. Recuperado de http://portal.mec.gov.br/seed/arquivos/pdf/tvescola/leis/lein9394.pdf.

Godoy, A. S. (2007). Competências adquiridas durante os anos de graduação: Um estudo de caso a partir das opiniões de alunos formandos de um curso de Administração de Empresas. Gestão \& Regionalidade, 23(68), 56-69.

Gomes, C. F. S., Xavier, L. H., \& Lemos, Z. (2015) A Liderança e a retenção de servidores na gestão pública. Revista de Carreiras e Pessoas (ReCaPe), 5(1),34-73.

Kato, M. F. (2007). Avaliação a partir da lógica das competências na educação profissional: Possibilidades. (Dissertação de Mestrado em Educação). Pontifícia Universidade Católica de São Paulo, São Paulo.

Keinert, T. M. M. (1994). Os paradigmas da administração pública no Brasil (1900-92). Revista de Administração de Empresas, 34(3), 41-48.

Kuenzer, A. Z. (2003). As relações entre conhecimento tácito e conhecimento científico a partir da base microeletrônica: Primeiras aproximações. Educar em Revista, 19(21), 43-69.

Kuenzer, A. Z. (2017). Competência como práxis: os dilemas da relação entre teoria e prática na educação dos trabalhadores. Boletim Técnico do SENAC, 30(3), 81-93.

Kuenzer, A. Z. (2018a). Conhecimento e competências no trabalho e na escola. Boletim Técnico do SENAC, 28(2), 2-11.

Kuenzer, A. Z. (2018b). Entrevista. Revista Pensar a Prática, 21(2), 1-8. 
Laffin, M. (2015). Graduação em Ciências Contábeis - a ênfase nas competências: Contribuições ao debate. Education Policy Analysis Archives, 23, 1-27.

Le Boterf, G. (1995). De la compétence: Essai sur um attracteur étrange. Paris: Éditions d'Organisation.

Le Boterf, G. (2003). Desenvolvendo a competência dos profissionais. Porto Alegre: Artmed.

Lei $n^{\circ}$ 9.394, de 20 de dezembro de 1996. Estabelece as diretrizes e bases da educação nacional (LDBN). Brasília: Congresso Nacional. Disponível em: http://portal.mec.gov.br/seed/arquivos/pdf/tvescola/leis/lein9394.pdf.

Lemos, R. B., Berni, R. De C. D., \& Palmeira, E. M. (2014). Liderança na gestão pública. Observatorio de La Economia Latino Americana, 194, 1-16. Recuperado de: http://www.eumed.net/cursecon/ecolat/br/14/gestao-publica.hmtl.

Longo, F. A. (2003). Consolidação institucional do cargo de dirigente público. Revista do Serviço Público, 54(2), 7-33.

Malhotra, N. K. (2012). Pesquisa de marketing: uma orientação aplicada. 6 ed. Porto Alegre: Bookman.

Manfredi, S. M. (1998). Trabalho, qualificação e competência profissional: das dimensões conceituais e políticas. Educação \& Sociedade, 19(64), 87-103.

Margetts, H. (2009). The Internet and public policy. Policy and Internet, 1, 1-21.

Maroco, J. (2003). Análise estatística com a utilização do SPSS. 2 ed. Universidade da Beira Interior, Covilhã. Lisboa: Edições Silabado.

Mclaughlin, K., Osborne, S., \& Chew, C. (2009). Developing the marketing function in U.K. public service organizations: The contribution of theory and practice. Public Money \& Management, 29(1), 35-42.

Meghnagi, S. (1992). Conoscenza e competenza. Torino: Loescher.

Moore, M. (2002). Recognizing value in policing. Washington, DC: Police Executive Research Forum.

Moore, M., \& Beninton, J. (2010). Public value: Theory and practice. London: Palgrave, Macmillan.

Newcomer, K. E. (1999). Preparação dos gerentes públicos para o século XXI. Revista do Serviço Público, 50(2), 5-18.

Nunes, S. C., \& Patrus-Pena, R. A. (2011). Pedagogia das competências em um curso de Administração: o desafio de passar do projeto pedagógico à prática docente. Revista Brasileira de Gestão de Negócios, 13(40), 281-299. 
Orletti, E. (2007). Novos desafios para a qualificação profissional. Trabalho Necessário, 5(5), $1-30$.

Osborne, S. (2010). The new public governance? London: Routledge.

Osborne, S., \& Brown, L. (2011). Innovation, public policy and public services: the word that would be king? Public Administration, 89(4), 1335-1350.

Patalas-Maliszewska, J., \& Hochmeister, M. (2011). Modeling strategic-knowledge-resource management based on individual competencies in SMES. Contemporary Economics, 5(2), $72-79$.

Pereira, M. S. A. (2013). Percepções de alunos concluintes sobre competências gerenciais adquiridas no curso de ciências contábeis oferecido por IES da cidade de São Paulo. (Dissertação de Mestrado em Ciências Contábeis). Fundação Escola de Comércio Álvares Penteado, São Paulo.

Pollitt, C., \& Bouckaert, G. (2004). Public management reform: a comparative analysis. Oxford: Oxford University Press.

Ramos, M. N. A. (2001). Pedagogia das competências: autonomia ou adaptação? São Paulo: Cortez.

Resolução $C F C n^{\circ} 560$ de 1983. Dispõe sobre as prerrogativas profissionais de que trata o artigo 25 do Decreto-Lei n. 9.295, de 27 de maio de 1946. Recuperado de http://www.portaldecontabilidade.com.br/legislacao/resolucaocfc560.htm.

Rezende, A. J., Slomski, V., \& Corrar, L. J. (2005). A gestão pública municipal e a eficiência dos gastos públicos: uma investigação empírica entre as políticas públicas e o Índice de Desenvolvimento Humana (IDH) dos municípios do estado de São Paulo. Revista Universo Contábil, 1(1), 24-40. Recuperado de: http://proxy.furb.br/ojs/index.php/universocontabil/article/view/75/36.

Ricardo, E. C. A. (2010). Discussion about learning competences: problems and alternatives. Cadernos de Pesquisa, 40(140), 605-628.

Ropé, F., \& Tanguy, L. (1997). Saberes e competências: o uso de tais noções na escola e na empresa. Campinas: Papirus.

Ruas, R. (2001). Desenvolvimento de competências gerenciais e contribuição da aprendizagem organizacional. In M. T. L. Fleury \& M. M. Oliveira (Orgs.), Gestão estratégica do conhecimento: Integrando aprendizagem, conhecimento e competências. São Paulo: Atlas, 242-267.

Ruas, R. L. (2005). Gestão por competências: uma contribuição à estratégia das organizações. In R. L. Ruas, C. S. Antonello \& L. H. Boff (Eds.), Aprendizagem organizacional e competências. Porto Alegre: Bookman, 34-54. 
Santos, A. N. Dos, Laimer, C. G., \& Laimer, V. R. (2016). Competências gerenciais e desempenho do gestor público. Revista da Universidade Vale do Rio Verde, 14(1), 132144.

Schwella, E. (2005). Inovação no governo e no setor público: desafios e implicações para a liderança. Revista do Serviço Público, 56(3), 259-276.

Sefiani, N., Boumane, A., Campagne, J., \& Bouami, D. (2012). Process of identifying competencies based on a functional approach. International Journal of Engineering Science and Technology, London, 4(1), 265-275.

Silva, F. S. (2007). A noção de competência no ensino superior: o curso de pedagogia da UFPB. RBPAE, 23(2), 315-326.

Slomski, V. (2005). Controladoria e governança na gestão pública. São Paulo: Atlas.

Slomski, V. G., Gomes, S. M. S., \& Guimarães, I. P. (2010). Gestão do projeto político pedagógico do curso de ciências contábeis e o currículo como instrumento de sua concretização. Revista de Contabilidade UFBA, 4(1), 36-55.

Souza, W. (1994). Interesse Público e resistência à mudança: estudo de casos em uma Secretaria de Estado. (Dissertação de Mestrado em Administração). Universidade Federal de Minas Gerais, Belo Horizonte.

Thomas, J. C. (2012). Citizen, customer, partner: Engaging the public in public management. New York: M. E. Sharpe.

Valadão Júnior, V. M., Buzatto, T. R. B., Medeiros, C. R. O., \& Heinzmann, L. M. (2017). Formação de competências do gestor público. Revista Capital Científico - Eletrônica, 15(1), 1-18.

Watson, T. J. (2005). Organização e trabalho em transição: da lógica "sistêmico-controladora" à lógica "processual-relacional". Revista de Administração de Empresas, 45(1), 14-23.

Zarifian, P. (2001). Objetivo competência: por uma nova lógica. São Paulo: Atlas. 